$\begin{array}{ll} & \text { Etnográfica } \\ \text { etnográfica } & \text { Revista do Centro em Rede de Investigação em }\end{array}$

Antropologia

vol. 17 (3) | 2013

Vol. $17(3)$

\title{
Filomena Silvano (ensaio) e João Pedro Rodrigues (documentários), De Casa em Casa: Sobre um Encontro entre Etnografia e Cinema
}

\section{Nuno Crespo}

\section{(2) OpenEdition}

\section{Journals}

\section{Edição electrónica}

URL: https://journals.openedition.org/etnografica/3275

DOI: 10.4000/etnografica.3275

ISSN: 2182-2891

\section{Editora}

Centro em Rede de Investigação em Antropologia

Edição impressa

Data de publição: 30 outubro 2013

Paginação: 655-657

ISSN: 0873-6561

\section{Refêrencia eletrónica}

Nuno Crespo, «Filomena Silvano (ensaio) e João Pedro Rodrigues (documentários), De Casa em Casa: Sobre um Encontro entre Etnografia e Cinema», Etnográfica [Online], vol. 17 (3) | 2013, posto online no dia 29 outubro 2013, consultado o 11 fevereiro 2022. URL: http://journals.openedition.org/etnografica/ 3275 ; DOI: https://doi.org/10.4000/etnografica.3275

\section{(c) (7) (8)}

Etnográfica is licensed under a Creative Commons Attribution-NonCommercial 4.0 International License. 
in the body, what is the novel conceptual mileage that we get out of it? One is definitely its centrality and the book clearly demonstrates this. But beyond its centrality, how far have we gotten into obtaining different understandings of it altogether? If the body acquires the role of transforming "slippery concepts", invisible, abstract, highly intellectual, spiritual or "soulful" issues into visible, "lived", "enacted" and concrete ones, then the body is not the site of difference but that of sameness and the universal (for an interesting discussion and effort to go beyond such and understanding of the body, see Eduardo Viveiros de Castro, "Cosmological deixis and Amerindian perspectivism", published in 1998 in the Journal of the Royal Anthropological Institute). This

Filomena Silvano (ensaio)

e João Pedro Rodrigues (documentários)

DE CASA EM CASA: SOBRE UM

ENCONTRO ENTRE ETNOGRAFIA

\section{E CINEMA}

Caldas da Rainha, Palavrão - Associa-

ção Cultural, 2012, 82 páginas + DVD, ISBN 978-989-97559-2-5.

Trata-se de uma edição de dois filmes e um texto. Portanto, um não vive sem o outro e só do encontro entre estas duas "peças" nasce o sentido do projeto. E o conceito de encontro é o que mais lhes convém, porque nem as imagens de João Pedro Rodrigues (JPR) partem das palavras de Filomena Silvano (FS) ou as usam, nem as palavras desta comentam as imagens daquele. A relação dá-se na total liberdade disciplinar does not sound very counter-intuitive to a Western ear but, on the contrary, as something too familiar. Therefore, I suspect that in order to gain new theoretical formulations of the body and the soul, what will also be welcome are accounts that not only go beyond their "great divide" but also the taken-for-granted understanding that one is the material and practical engagement of the other's inherently abstract and invisible nature.

\section{Anastasios Panagiotopoulos}

Centro em Rede de Investigação em Antropologia, Faculdade de Ciências Sociais e Humanas da Universidade Nova de Lisboa, Portugal anasta4@hotmail.com de cada uma das "peças" e no modo como, sem condescendências, cada um dos autores obedece às regras, princípios e formalismos do seu campo de atuação.

O texto de FS mostra que o exercício cinematográfico de JPR apresenta um conjunto forte de questões associadas à emigração e ao modo como no contexto da deslocação social, cultural e afetiva a identidade e a cultura se desenvolvem. Estes filmes permitiram à antropóloga encontrar o seu objeto de estudo: "Parece-me que ele [o filme do JPR] dá muito mais conta de algumas das minhas questóes do que as aproximações que os antropólogos lhes fazem. O filme não permite fazer uma leitura linear do espaço, mas consegue dar conta das minhas interrogações sobre o facto de a vida daquelas pessoas ser aquele permanente estar em trânsito. A opção do 
JPR [de] filmar daquela maneira aquelas pessoas prende-se com questões de cinema, mas foi ele que me permitiu observar aquilo [de] que andava à procura" (entrevista publicada no suplemento Ípsilon do jornal Público, 15/03/2013). Portanto, é sobre esta vantagem do cinema que FS trabalha, não camuflando a sua natureza muitas vezes performativa e sempre projetiva, ou seja, trata-se de cinema e, portanto, há encenação, há pose, há construção e, sobretudo, há por parte de quem é filmado a consciência da presença da câmara e da sua ação de fixação das imagens.

A motivação de todo o projeto teve que ver com as questões da "deslocalização da cultura e com as formas de a dar a ver. Queríamos mostrar como é que os membros de uma família, de origem portuguesa mas em viagem constante entre duas aldeias de Trás-os-Montes e a cidade de Paris, constroem os seus próprios universos culturais e, consequentemente, as suas identidades. Nesse ano [refere-se a 1997] acompanhámos e filmámos o quotidiano da família nos percursos entre as suas duas casas de Paris e as casas dos pais de ambos em Trás-os-Montes. Entretanto foi-se desenhando, face ao desejo da família de visitar a Expo'98, um segundo projeto de filme, a rodar em Lisboa durante o verão de 1998" (p. 9).

Se uma das premissas deste projeto é dar a ver os mecanismos da construção da identidade e da cultura, a outra é fazê-lo através do cinema, ou seja, não é um meio neutro e nem JPR um realizador qualquer. Escreve FS: "quando aceitei trabalhar com o JPR num projeto de documentário, fi-lo com a consciência de que ia trabalhar com um cineasta. Ou seja, com alguém para quem filmar um documentário era um exercício de cinema (e não um exercício etnográfico, sociológico ou jornalístico). Quero com isto dizer que desde o início foi claro para mim que estava a acompanhar a realização de um filme que, na sua essência, não era determinado por questões conceptuais que tivessem origem no saber da antropologia" (p. 10).

Ao longo do livro FS descreve com muita precisão e profundidade os problemas relacionados com os lugares da cultura (vistos da perspetiva do emigrante), as viagens à terra e o facto de o ser emigrante implicar um conjunto forte de traços característicos relacionados com o modo como cada um imagina ser a sua nação e o seu papel na construção dessa ideia, mas na introdução FS consegue, numa brilhante síntese, dar conta do modo como o cinema (sempre diferente do filme etnográfico) consegue levar vantagem sobre a escrita corrente da antropologia: “o João Pedro conseguiu aî ultrapassar o problema, tão frequente na escrita etnográfica e no filme documental, da ausência das pessoas. Nesse filme [refere-se a "Esta é a minha casa"], aquilo que mais me impressionou foi a força, inequivocamente verdadeira, dos corpos de José e de Jacinta. Uma presença cuja existência é obviamente cinematográfica" (p. 11). E umas linhas mais à frente acrescenta: “... é como se os corpos contivessem, logo na sua primeira aparição, as verdades dos personagens" (p. 11).

E esta "verdade" dá o testemunho que a etnografia tradicional nunca poderia revelar, não só pelas limitações da escrita metodológica da etnografia, mas também porque a cena antropológica, ou seja, a identidade das pessoas, é composta por elementos mutantes e multissituados, ou seja, é feita de percursos. O cinema, através da montagem e do modo como faz aparecer simultaneamente elementos tão díspares, consegue mostrar esse movimento e permanente metamorfose.

O movimento, que é o movimento dos filmes de JPR e do texto de FS, é feito entre cinco casas distintas distribuídas entre Paris e Trás-os-Montes, entre a exiguidade de uma casa de porteira num prédio da Paris 
burguesa, a vivenda de fim de semana nos arredores da capital francesa e as casas da família na aldeia. E é neste contexto que aquelas pessoas se constroem. Escreve FS: "queria perceber como é que os seus membros construíam as suas identidades pessoais e como é que cada um representava a sua condição de pessoa em constante movimento entre a ruralidade de um país periférico e a urbanidade de um país central" (p. 20). Trata-se aqui de uma tensão entre mobilidade e localização que não é só geográfica, mas relativa ao modo de vida e à configuração das escalas de valor.

Se a análise do discurso e das práticas sociais permite traçar um quadro de identificação cultural, os filmes permitem perceber o modo como o corpo tem um papel fundamental nos processos descritos. Essa ideia de que a cultura se toma num corpo (e a que FS chama embodiment) só muito raramente é assumida pela etnografia, ainda que se saiba não ser possível uma

José Antonio Cortéz Vázquez

NATURALEZAS EN CONFLICTO: CONSERVACIÓN AMBIENTAL Y ENFRENTAMIENTO SOCIAL EN EL PARQUE NATURAL CABO DE GATA-NÍJAR Valência, Germania, 2012, 323 páginas, ISBN: 978-84-15660-29-3.

Cortéz Vázquez apresenta neste livro os resultados de um estudo sobre o Parque Natural Cabo de Gata-Níjar (PNGN) na Andaluzia (Espanha). Por um lado, tenta captar os impactos sociais (e naturais) de uma política de conservacionismo cultural cultura sem corpo. Escreve FS: "No caso de José [o homem do documentário], de uma forma muito mais óbvia do que no caso de Jacinta, a diversidade das formas que o seu corpo assumia foi uma revelação. Nas imagens visionadas foi possível identificar pelo menos quatro formas corporais, a que chamarei, para organizar as ideias, o "corpo do imigrante", o "corpo do artesão", o "corpo do emigrante" e o "corpo do crente" (p. 61). A descoberta é feita pelo olhar do cinema, porque esse conjunto de corpos se forma a partir do estabelecimento de diferenças subtis, estéticas e expressivas, que só o mais rigoroso exercício do cinema pode tornar comunicáveis. Ou seja, o cinema torna presente o corpo que é o objeto fundamental da antropologia, mas quase sempre ausente.

\section{Nuno Crespo}

Instituto de História da Arte, Universidade Nova de Lisboa, Portugal nunocrespo.iha@fcsh.unl.pt

e natural que tem sido implementada pela administração ambiental andaluza nas últimas décadas, e, por outro, o modo como as populações humanas têm interagido no território ao longo do tempo com os elementos (recursos) agora patrimonializados. O livro dá especial relevo às medidas proibitivas e regulatórias com o objetivo de garantir usos respeitosos do meio ambiente e suas implicações (materiais e simbólicas) sobre diferentes grupos sociais, em particular aqueles que sempre têm vivido no PNGN, não esquecendo uma retórica ambientalista ("verde") mais global que tem ajudado à própria redefinição da natureza e do mundo. $\mathrm{O}$ autor 